\title{
MILLAL HINGUS HINGAB JA HINGUSELE LÄHEB?
}

Omal ajal, kui püüdsin aru saada mõnest Johannese evangeeliumi päätükist kreeka originaalis, rabas mind üks kirjakoht. Joh 3,8, mis Toomas Pauli ja Uku Masingu tõlkes kõlab: „Tuul puhub, kuhu ta tahab, ja sa kuuled ta häält, kuid ei tea, kust ta tuleb ja kuhu läheb. Niisama on kõigiga, kes on sündinud Vaimust."

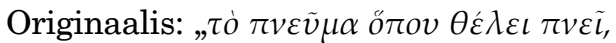

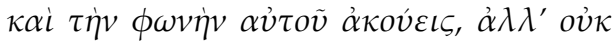

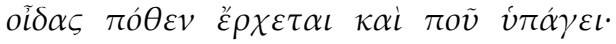

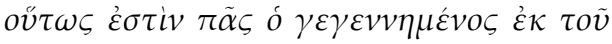
$\pi v \varepsilon \dot{v} \mu \alpha \tau o \varsigma . "$ Kommentaaris on öeldud: „Semi keeltes, s.h. heebrea ja aramea keeles ning kreeka keeles on "tuul” ja „vaim” üks ja sama sõna (kr. pneuma); ei ole võimalik tõmmata piiri, millal siin „tuul”, millal „vaim” või „Vaim”.”

Kommentaatorid räägivad ühest ja samast sõnast, mille taga on eri mõisted, eeldades, et tuul ja vaim siiski erinevad. Kuid ons see tingimata nii? Võibolla oleks mõtet mõelda, et semiitidel ja paljudel teistel rahvastel oli ja ilmutas end inimese või Jumala hinguses nende vägi. Ning et Jumal või üks tema avaldumisvorm oligi hingus, ka tuulehingus, taevaste tuul. Inimese teeb elavaks inimeseks tema hingus, hing. Eks siis ole ka tuul kellegi hingus, kellegi hing. Piibli loomislugu algab sellega, et Jumala vaim oli lehvimas vete kohal. Siin on Jumala vaim ruach elohim. Sõna ruach võibki tähendada nii hinge, tuult kui vaimu. Inimese loomiseks puhus Jumal oma hingeõhku inimese sõõrmetesse. Siin on hingeõhu tähenduses kasutatud teist sõna - nišmah, mis vahel esineb

${ }^{1}$ Uus Testament ja psalmid ehk Vana Testamendi laulud. Tlk Toomas Paul, Uku Masing. Tallinn: Olion, 1990. koos ruach'iga, näiteks 1Ms 7,22: nišmat ruach hajjim - eluhinguse hingus. Nii tuleb siingi välja elu ja hingamise seos: eluvaim on eluhingus. Inimene on selles ilmanägemises koos maamullast ja Jumalalt saadud eluhingusest, mis kord läheb Jumala juurde tagasi, nagu on öeldud Koguja raamatu viimases päätükis: „Siis läheb põrm tagasi maasse, kust ta on, ja hing tagasi Jumala juurde, kes ta siia saatis" $(\operatorname{Kog} 12,7){ }^{2}$

Tsiteeritud kreekakeelne lõik tunnistab kommentaariski öeldut: mitmete vanade rahvaste kujutluses oli inimese hing otseselt seotud hingamisega, hingeõhuga, hingusega. Selles hinges, hingeõhus oli inimese elujõud, eluvägi, mille ta võis olla saanud kõrgemalt Väelt. Nii tähendasid vähemalt hellenistlikus Lähis-Idas heebrea-aramea ruach ja kreeka pneuma enamvähem üht ja sama. Ei olnud vaja ühtsama sõna tõlkida kahel moel. Seda ei pidanud tegema ka Piibli esimese, hiljem katoliku kiriku poolt kanoniseeritud ladinakeelse tõlke, Vulgata kompileerija ja redigeerija Hieronymus. Tema tekstis (nagu juba varasemates tõlgetes, nn „Vetus latina's”) on pneuma vasteks saanud spiritus: „Spiritus ubi vult spirat et vocem eius audis sed non scis unde veniat et quo vadat sic est omnis qui natus est ex Spiritu." Sõna spiritus tähendab samuti algselt hingust, hingeõhku, on aga läänemaises teoloogias ja filosoofias saanud juurde tugeva intellektuaalse maigu: sõna spirituaalne, eesti keeles enamastivaimne on nüüd lähedane sõnale intellektuaalne. Mis on ilmselt nihutanud ka vanemat kujut-

\footnotetext{
${ }^{2}$ Vello Salo ja Jaan Kaplinski tõlkes.
} 
lust Jumalast kui dünaamilisest väest, loovast hingusest ligemale kujutlusele Jumalast kui intellektist. Johannese evangeeliumi lause (Joh 4,24) $\pi v \varepsilon \tilde{v} \mu \alpha \delta$ $\theta \varepsilon o ́ s$, ladina Vulgatas Spiritus est Deus, tähendab algselt muud mõtet kui Jumal on vaim, Gott ist Geist või God is Spirit. Vabas eesti tõlkes võiks ehk öelda, et Jumal on Vägi, Hingusevägi.

Sõna vaim nagu saksa Geist või inglise keelde laenatud spirit tähendavad meil siis ühelt poolt intellekti, teiselt poolt aga midagi tondi või kehatu kummituse taolist. Nii Juudamaal ja Galileas, nagu laiemalt hellenistlikus ilmas, ei mõistetud Jumalat spiritistlikult mingi vaimu või astraalkehana ega spiritualistlikult superintellekti-superkompuutrina. Tõlgetes on kaduma läinud pneuma algne hinguse kui loova, parandava, toimiva väe tähendus. Siit mõned segadused ja raskused Piibli tõlkimisel, mis on ühised paljudele Euroopa rahvastele.

Asja teeb keerulisemaks ka see, et vanemas eesti keeles tähendab hingamine ka puhkamist. Vanas 1863. aasta Piiblis loeme: „Ja Jummal oli seitsmel päwal omma teggemist lõppetanud, mis ta olli teinud, ja hingas seitsmel päwal keigest ommast teggemissest, mis ta olli teinud" (1Ms 2,2). Nüüdki nimetatakse pühapäeva kirikutraditsiooni järgi hingamispäevaks, mitte puhkepäevaks. Lõuna-Eestis, vähemalt vanal Võrumaal püsis see keelepruuk kauem, ka minu vanaema teadis ütlemist ,henge haardma”. Sõna puhkama tähendas minu lapsepõlvekodus ka puhumist; kui lapse sõrm oli häda saanud, öeldi „puhka pääle". Nii on eesti keeles nüüdki puhkamine ja hingamine etümoloogiliselt ja semantiliselt üksteisele väga lähedased sõnad, mõnikord sünonüümid. Siit sünnibki vastuolu. Ühelt poolt on ilmamaa ja inimese loomisel otsustavalt tegev olnud Jumala loov hingus, ruach; Jumal ise on hingus, hing (pneuma, spiritus), inimene saab elusaks olevuseks, kui Jumal oma eluhingest midagi tema sõõr- metesse puhub. Teiselt poolt tähendab see, et Jumal seitsmendal päeval oma loovast tegevusest hingab, seda, et see loov hingus mingil ajal tegevuses polnud, Jumala hingus „oli hingusel”.

Religiooniloolane ja filoloog Marju Lepajõ $^{3}$ kirjutab mulle: „Nt. $1 \mathrm{Kr}$ 16,18 on kreeka tekstis „nad andsid pausi/ puhkamise mu vaimule/pneumale", mis sisaldaks endas, et pneuma ei pea puhates hingama ega puhuma, siis eesti tõlkes on: „nad on andnud hingamist mu vaimule". $2 \mathrm{Kr} 7,13$ on lihtsalt tõlgitud „vaim on leidnud kosutust”. 1Pt 4,14 kreeka tekstis „õndsad olete [---], sest siis puhkab/teeb pausi teie peal Jumala pneuma", s.o. vaibub, aga eesti tõlkes: „siis hingab teie peal Jumala vaim”.”

Siia võib lisada, et probleemi nende kohtade tõlkimises on ilmselt nähtud, millest siis katsed hinge hingamist tõlkes kuidagi arusaadavalt edasi anda. Vanemates Piibli väljaannetes on $1 \mathrm{Kr}$ 16,18 tõlgitud näiteks „nemad on jahutanud minu ja teie vaimu”. Nii on 1988. aastal Soome piibliseltsi välja antud Piiblis, nii ka juba tsiteeritud 1863. aasta Piiblis, kus loeme „nemmad on minno ja teie waimo jahhutanud”.

Puhkamisest rääkides kasutavad eri keeled suuresti sõnatüvesid, millel on teine põhitähendus. Nagu meie hingama, vene omdblxams, inglise rest, soome levätä, saksa sich erholen, prantsuse se reposer. Oleks viga automaatselt arvata, et on olemas mingi ajatu mõiste, mida väljendavad need sõnad, ja et nende taga on mingi selgelt piiritletud tükk reaalsust. Puhkamise semantika on keerulisem ja laialivalguvam. See, et me nimetame raske füüsilise pingutuse järel hingetõmbamist samamoodi puhkamiseks kui lustlikku ajaveetmist, meele lahutamist ööklubis, ei ole enesestmõistetav. Mõistes on koos mitmeid komponente, mida võivad märkida mitmed eri

\footnotetext{
${ }^{3}$ Tänan teda asjalike ja julgustavate mär-
} kuste eest. 
sõnad. Nagu puhkama ja hinge tõmba$m a$, mis algselt on olnud üsna lähedase tähendusega, nüüd aga enam mitte.

Kui minna tagasi algusse, siis olemasolevatel andmetel esimene puhkaja maailmas oli Jumal ise. Eesti vana Pühakirja järgi ta hingas. Heebrea originaalis loeme: wayišbot [Elohim] bayom hašebi’i. Puhkamist tähendab siin sõna yišbot, mille tüvi on šbt, sama, mis sõnas šabat - sabat, meie hingamispäev. Tüve põhitähendus on 'seisma jääma, kinni pidama'. Teistes keeltes on metafoorselt puhkamisest rääkides rõhutatud muud, näiteks liikumata olemist (inglise rest, saksa ruhen, ladina quiescere, soome levätä). Eesti ja vene keeles (omdbxamb) aga on üldisema tähenduse saanud just raske pingutuse järel hingetõmbamist, hinge haaramist märkiv sõna.

Enamikus slaavi keeltes ei käi hingamine ja puhkamine vene keele kombel kokku, domineerib teine tüvi, mille tuletised on poola spoczywać, tšehhi odpočivati, kirikuslaavi noчúmu. Kirikuslaavi Piiblis loeme: почú [Бо́zъ] въ де́нъ седми́ú. Omdьххать vasted pole muudes slaavi keeltes siiski tundmata: rumeenia keeles on põhiline sõna puhkamise jaoks slaavi laen (a)odihni. Omaette küsimus on, kas vene keelt on kallutanud puhkamist hingamisena nägema mingi soomeugri substraat. Võimatu see pole, hingamine ja puhkamine on ersa keeleski samatüvelised: oŭмe tähendab hinge ja hingamist, oŭмсемс - puhkama. Ent hingamine ja puhkamine on nii semantiliselt kui etümoloogiliselt lähedased mõisted õige erinevates keeltes. Muuhulgas ka hiina keeles: $x i ́$ tähendab nii hinga- mist kui puhkamist, ent ka vaibumist ja hääbumist. Siin on hää paralleel meie hingamise kahele tähendusele, tasub mõelda ka väljendile „läks hingusele”. Ent hiina keeles on teine sõna - Läänes ehk tuttavamgi qì, mis tähendab algselt auru, hiljem igasugust gaasi, udu, vinet, kuid ka hingust, niisamuti väge, jõudu. $Q i$ on tähenduselt üsna lähedane semiidi sõnale, mis heebrea keeles on ruach, või kreeka sõnale pneuma.

Sõnadele nagu heebrea ruach, kreeka pneuma, ent isegi hiina qì on eesti ja mulle tuttavate soome-ugri rahvaste keeltes selget vastet raske leida. Eestlastele oli ja on hingus seotud pigem puhkusega, mitte tööga, loova tegevusega. Samamoodi ei ole sellist vastet olnud mõnes muuski Euroopa keeles väljaspool kunagise hellenistliku maailma piire. Ka prantsuskeelne sõna respirer tähendab hingamist, ent ka hinge tõmbamist nagu eesti keeleski. Ka saksa Atem holen tähendab hingetõmbamist nagu inglise breather. Kuigi neis keeltes on puhkamise tähenduses põhiliselt käibel teine sõna: prantsuse se reposer, inglise (have a) rest, saksa ruhen, sich erholen. Ilmselt on mitmed põhjapoolse Euraasia rahvad kuulunud teise kultuuriruumi kui lõunapoolsed. Siit siin vastete otsimine, laen või olemasoleva, aga üpris teise tähendusega sõna kasutamine, mis teksti mõtet võib tõsiselt muuta, tehes Jumalast loova hinguse asemel spirituaalse ülimatemaatiku või spiritistide kehatu keha. 